\title{
Modeling of Intermetallic Compounds Growth Between Dissimilar Metals
}

\author{
LI WANG, YIN WANG, PHILIP PRANGNELL, and JOSEPH ROBSON
}

\begin{abstract}
A model has been developed to predict growth kinetics of the intermetallic phases (IMCs) formed in a reactive diffusion couple between two metals for the case where multiple IMC phases are observed. The model explicitly accounts for the effect of grain boundary diffusion through the IMC layer, and can thus be used to explore the effect of IMC grain size on the thickening of the reaction layer. The model has been applied to the industrially important case of aluminum to magnesium alloy diffusion couples in which several different IMC phases are possible. It is demonstrated that there is a transition from grain boundary-dominated diffusion to lattice-dominated diffusion at a critical grain size, which is different for each IMC phase. The varying contribution of grain boundary diffusion to the overall thickening kinetics with changing grain size helps explain the large scatter in thickening kinetics reported for diffusion couples produced under different conditions.
\end{abstract}

DOI: $10.1007 / \mathrm{s} 11661-015-3037-7$

(C) The Author(s) 2015. This article is published with open access at Springerlink.com

\section{INTRODUCTION}

INTERMETALLIC compounds (IMCs) are often formed at the interface between dissimilar metals during diffusion bonding, welding, and mechanical milling, etc. ${ }^{[1-5]}$ The IMCs usually have properties that are very different from the base metals and thus have a critical effect in controlling overall joint performance. Diffusion bonding is a widely used technique to study the growth kinetics of IMC phases between dissimilar metals. In a diffusion-bonded couple, two different metals are brought into intimate contact and then annealed at an appropriate temperature below the eutectic melting temperature. Solid-state diffusion occurs between the two metals and leads to the formation of one or more IMC phases at the interface between the two metal substrates once a critical level of enrichment is reached. Once the IMC has formed a continuous layer at the interface, further growth is only possible by diffusion through the IMC itself, and an abrupt change in kinetics is often observed. To produce a bond with good mechanical properties, it is usually essential to maintain the IMC layer thickness below a critical value, since IMC phases are typically brittle and can lead to a marked loss in joint toughness if allowed to become too thick. ${ }^{[5]}$ Therefore, many researchers have studied reactive diffusion in a large number of binary alloy diffusion couples and there have also been several attempts to model the evolution of the IMC layer. ${ }^{[1-5]}$ It is widely accepted that reactive diffusion is mainly

LI WANG, Engineer, formerly with the Grosvenor Street, Manchester M13 9PL, UK, is now with the Jaguar Land Rover Company, Coventry, UK. Contact e-mails: lwang9@jaguarlandrover. com; liwangmaterials@outlook.com YIN WANG, Ph.D. Student, PHILIP PRANGNELL, Professor, and JOSEPH ROBSON, Reader, are with the University of Manchester.

Manuscript submitted March 8, 2015.

Article published online July 8, 2015 governed by volume diffusion, ${ }^{[1-3,9,10]}$ and the thickness of an IMC phase generally follows a parabolic relationship with annealing time. ${ }^{[3,5,9,10]}$

It is common in analyzing reactive interdiffusion to measure the thickness of the IMC layer as a function of time under isothermal conditions and then fit the data to a parabolic law of the form:

$$
l^{2}=k t
$$

where $l$ is the layer thickness, $k$ the parabolic coefficient, and $t$ is time. By performing such experiments at a range of temperatures, an effective activation energy $Q$ and the pre-exponent factor $k_{0}$ for the thickening kinetics are obtained from the Arrhenius equation. ${ }^{[1-3,10]}$ According to Kidson, ${ }^{[11]}$ the parabolic coefficient is a mixture of many different parameters, and the simple Arrhenius dependence on temperature is not strictly correct. It is found that the values of activation energy that are derived from such experiments show a large variation even for the same system between studies, e.g., the activation energy for thickening of the $\mathrm{Al}_{3} \mathrm{Mg}_{2}$ phase, which is the main IMC phase in the $\mathrm{Al}-\mathrm{Mg}$ binary diffusion system, is reported in a range from 65 to $86 \mathrm{~kJ} / \mathrm{mol}$, which is a very significant difference given the exponential dependence of kinetic processes on $Q .^{[5,10,12,13]}$

The diffusion coefficient is the key parameter to describe the diffusivity of an element. ${ }^{[14]}$ Since the IMC growth is mainly controlled by volume diffusion, the interdiffusion coefficient can be used to compare the growth rates between IMC phases. However, the interdiffusion coefficient of an IMC phase cannot be simply obtained, and must usually be extracted from experimental measurements using a number of modeling techniques. ${ }^{[1,2,12,15]}$ The Boltzmann-Matano method ${ }^{[15]}$ is one of the most successful models to calculate the interdiffusion coefficient of IMC phases. This method 
requires measuring the composition profile along the IMC layers, based on the calculation of interdiffusion fluxes of individual components. Kajihara ${ }^{[1,2]}$ also developed a model to calculate the interdiffusion coefficient of the IMC phase in a binary alloy system for the case where only one IMC forms. In Kajihara's model, the composition profile is not required, but the compositions at each side of each interface are necessary. ${ }^{1,2]}$ Another advantage of this model is that it can also be utilized in reverse (once the interdiffusion coefficient in the IMC is known) to predict the IMC growth kinetics. However, this model cannot be applied for many practically important binary alloy systems where two or more IMC phases form.

In order to predict the IMC growth kinetics, interdiffusion coefficients of all the phases are required. However, a wide range of interdiffusion coefficient values for each IMC phase is often reported, making it difficult to accurately predict the thickening kinetics. $^{[10,12,13]}$ A possible reason for this is that the interdiffusion values are derived from experiments that do not explicitly consider the different pathways that contribute to diffusion, e.g., grain boundary and lattice diffusion. Grain boundaries provide fast diffusion pathways, so the interdiffusion coefficient depends on the availability of such pathways, i.e., on grain size and shape ${ }^{[14,16]}$ Few researchers consider the effect of grain boundary diffusion on the effective interdiffusion coefficient of IMC phases. ${ }^{[1-3,12,13]}$ However, this can be important, since there are significant differences in grain size depending on the process used to form the IMC phase. Part of the scatter in the effective interdiffusion coefficients reported for IMC phases is undoubtedly due to variations in grain size between specimens, which is often neglected.

This paper focuses on the industrially important case of aluminum to magnesium alloy couples. Such couples are of importance in lightweight vehicle structures produced by dissimilar metal joining of magnesium and aluminum alloys. In Al-Mg couples, two different IMC phases $\mathrm{Mg}_{17} \mathrm{Al}_{12}$ and $\mathrm{Al}_{3} \mathrm{Mg}_{2}$ are typically observed $^{[5,9,10,12,17-19]}$ and have different growth kinetics. ${ }^{[9,10,12]}$ Once the IMC layers exceed a critical thickness they are known to produce a sharp reduction in the strength and ductility of the dissimilar metal joint. Understanding how to control IMC growth in such a system containing multiple IMCs is thus of great practical as well as scientific importance.

The aim of the present work is to develop a model to predict growth kinetics of each IMC phase in a binary alloy system where multiple phases can form. The effect of grain size on diffusion is also explicitly considered so that results from conditions that lead to a difference in grain size can be compared. The basic approach is from Kajihara's mode ${ }^{[1,2]}$ extended to include multiple phases. A classical grain growth model $^{[20]}$ is applied to predict IMC grain size. The model is demonstrated by application to the case of $\mathrm{Al}-\mathrm{Mg}$ alloy couples produced by ultrasonic welding and diffusion annealing.

\section{EXPERIMENTAL PROCEDURES}

1-mm-thick sheets of $\mathrm{Mg}$ alloy AZ31 (Mg3 wt pet Al-1 wt pet $\mathrm{Zn}$ ) and Al alloy AA6111 (Al0.85 wt pet $\mathrm{Si}-0.75$ wt pet $\mathrm{Mg}-0.7$ wt pet $\mathrm{Cu}$ ) were used in the present work. To provide a consistent starting condition, the two sheets were welded using a Sonobond dual reed ultrasonic welding machine for a very short welding time ( 0.3 second). This minimizes the formation of IMC during the welding process itself but allows for a metallurgical bond to form between the magnesium and aluminum alloy by breaking up the surface oxide. Then, the welded couples were isothermally annealed at $633 \mathrm{~K}$ and $673 \mathrm{~K}\left(360{ }^{\circ} \mathrm{C}\right.$ and $\left.400{ }^{\circ} \mathrm{C}\right)$, or $693 \mathrm{~K}\left(420{ }^{\circ} \mathrm{C}\right)$ for various times to study the growth kinetics of IMC layers. Samples were cut through the weld centerline, and then prepared using standard metallographic techniques. The IMC layers were investigated using an FEI Magellan high-resolution field emission gun scanning electron microscopy (FEGSEM) and high-resolution electron backscatter diffraction (EBSD) under an acceleration voltage of $20 \mathrm{kV}$ with a step size of $0.01 \mu \mathrm{m}$ on samples prepared by removing surface distortion with a FEI Quanta 3D dual-beam focused ion beam (FIB).

\section{MODELING AND CALCULATIONS}

\section{A. Dual IMC Phase Growth Model}

In many important binary metal couples, the binary system is characterized by limited solid solubility and the formation of intermetallic compounds at intermediate compositions. During reactive interdiffusion, IMC will form once sufficient diffusion across the interface has occurred, and it will then grow. The nucleation stage is often ignored since it usually occurs at very short times with respect to total annealing time. Therefore, the final thickness of the IMC layer is controlled mainly by growth. The growth kinetics of IMC phases are mainly controlled by the interdiffusion coefficient. Kajihara ${ }^{[1]}$ developed a model to calculate the effective interdiffusion coefficient of an IMC phase from a binary system where only one compound will be formed. Since the thickness of an IMC phase is usually quite small with respect to the total specimen size, the two metal substrates can be considered as semi-infinite boundaries. The composition of an element at the two sides of an interface can be calculated using thermodynamic calculation software if both sides of the moving interface are assumed to be in a local equilibrium state. In Kajihara's model, ${ }^{[1,2]}$ the moving rate of the interface is assumed to be controlled by the volume diffusion in the neighboring phases, and all other effects caused by impurities or defects are ignored. It is also assumed that the volume diffusion coefficient is independent of phase composition.

To extend this approach to a system with two IMC phases, consider a hypothetical situation: a binary alloy system A-B forms two IMC phases $\mathrm{A}_{2} \mathrm{~B}$ ( $\gamma$-phase) and $\mathrm{AB}$ ( $\beta$-phase) at the interface between $\mathrm{A}$ and $\mathrm{B}$, 
respectively, as schematically illustrated in Figure 1. The initial boundary conditions are

$$
\begin{aligned}
& C_{\mathrm{A}}(x, t=0)=C_{\mathrm{A} 0} \\
& C_{\mathrm{B}}(x, t=0)=C_{\mathrm{B} 0} .
\end{aligned}
$$

During growth of intermetallic phases, the boundary conditions of each phase can be described by

$$
\begin{aligned}
& C_{\mathrm{A}}\left(x=z_{a b}, t>0\right)=C_{\mathrm{A} \gamma} \\
& C_{\gamma}\left(x=z_{a b}, t>0\right)=C_{\gamma \mathrm{A}} \\
& C_{\gamma}\left(x=z_{b c}, t>0\right)=C_{\gamma \beta} \\
& C_{\beta}\left(x=z_{b c}, t>0\right)=C_{\beta \gamma} \\
& C_{\beta}\left(x=z_{c d}, t>0\right)=C_{\beta \mathrm{B}} \\
& C_{B}\left(x=z_{c d}, t>0\right)=C_{\mathrm{B} \beta} .
\end{aligned}
$$

Since there are two intermetallic phase, two more boundary conditions are added compared to Kajihara's model for a single IMC. In Eqs. [2c] through [2h], $z_{a b}$, $z_{b c}$, and $z_{c d}$ are the distance of each interface to the original interface between $\mathrm{A}$ and $\mathrm{B}$, as shown in Figure 1, and their values can be negative, zero, or positive depending on their position to the original A-B interface. According to Kajihara ${ }^{[1]}$ and invoking Kidson's model ${ }^{[11]}$ for the growth kinetics of multiple intermetallic phases in a binary system, the distance values can be calculated by Eqs. [3a] through [3c]:

$$
\begin{aligned}
& z_{a b}=K_{\mathrm{A} \gamma} \sqrt{4 D_{\mathrm{A}} t}=K_{\gamma \mathrm{A}} \sqrt{4 D_{\gamma} t} \\
& z_{b c}=K_{\gamma \beta} \sqrt{4 D_{\gamma} t}=K_{\beta \gamma} \sqrt{4 D_{\beta} t}
\end{aligned}
$$

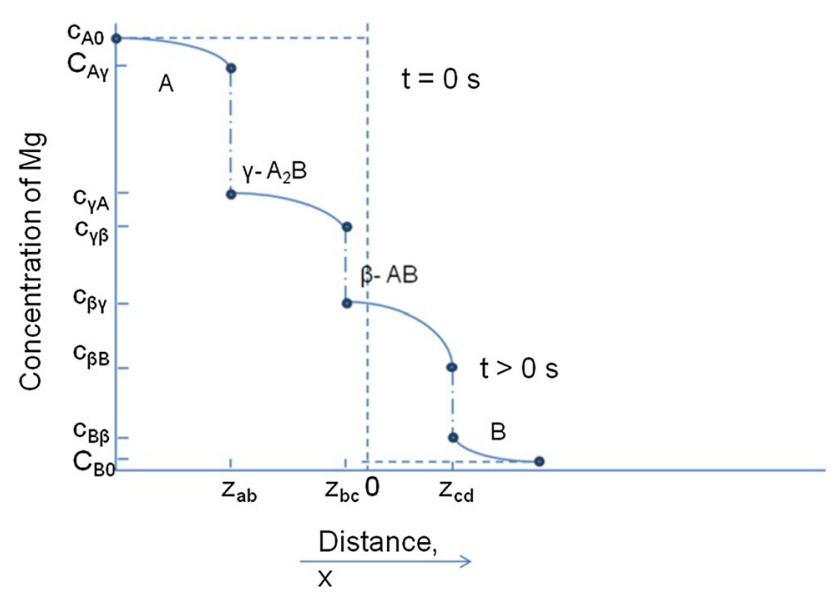

Fig. 1-Concentration of A along the IMC layers for a hypothetical $\mathrm{A}-\mathrm{B}$ system in which two IMC phases form, $\mathrm{A}_{2} \mathrm{~B}$ and $\mathrm{AB}$.

$$
z_{c d}=K_{\beta \mathrm{B}} \sqrt{4 D_{\beta} t}=K_{\mathrm{B} \beta} \sqrt{4 D_{\mathrm{B}}} t,
$$

where $t$ is time, $D_{\mathrm{A}}, D_{\gamma}, D_{\beta}$, and $D_{\mathrm{B}}$ are the interdiffusion coefficient of the A substrate, the $\gamma-A_{2} B$ phase, the $\beta-\mathrm{AB}$ phase, and the $\mathrm{B}$ substrate, respectively. $K_{\mathrm{A} \gamma}$, $K_{\gamma \mathrm{A}}, K_{\gamma \beta}, K_{\beta \gamma}, K_{\beta \mathrm{B}}$, and $K_{\mathrm{B} \beta}$ are dimensionless proportionality coefficients, which are related to the initial boundary conditions. According to Kajihara's model, incorporating the initial and boundary conditions shown in Eqs. [2a] through [2h] into Fick's 2nd law, the proportionality coefficients have the following relationships with the concentration profile $e^{[1,2]}$.

$$
\begin{aligned}
C_{A \gamma}-C_{\gamma \mathrm{A}}= & \frac{C_{\mathrm{A} 0}-C_{\mathrm{A} \gamma}}{K_{\mathrm{A} \gamma} \sqrt{\pi}\left[1+\operatorname{erf}\left(K_{\mathrm{A} \gamma}\right)\right]} \exp \left[-\left(K_{\mathrm{A} \gamma}\right)^{2}\right] \\
& +\frac{C_{\gamma \beta}-C_{\gamma \mathrm{A}}}{K_{\gamma \mathrm{A}} \sqrt{\pi}\left[\operatorname{erf}\left(K_{\gamma \beta}\right)-\operatorname{erf}\left(K_{\gamma \mathrm{A}}\right)\right]} \exp \left[-\left(K_{\gamma \mathrm{A}}\right)^{2}\right]
\end{aligned}
$$

$$
\begin{aligned}
C_{\gamma \beta}-C_{\beta \gamma}= & \frac{C_{\gamma \mathrm{A}}-C_{\gamma \beta}}{K_{\gamma \beta} \sqrt{\pi}\left[\operatorname{erf}\left(K_{\gamma \beta}\right)-\operatorname{erf}\left(K_{\gamma \mathrm{A}}\right)\right]} \exp \left[-\left(K_{\gamma \beta}\right)^{2}\right] \\
& +\frac{C_{\beta \mathrm{B}}-C_{\beta \gamma}}{K_{\beta \gamma} \sqrt{\pi}\left[\operatorname{erf}\left(K_{\beta \mathrm{B}}\right)-\operatorname{erf}\left(K_{\beta \gamma}\right)\right]} \exp \left[-\left(K_{\beta \gamma}\right)^{2}\right]
\end{aligned}
$$

$$
\begin{aligned}
C_{\beta \mathrm{B}}-C_{\mathrm{B} \beta}= & \frac{C_{\mathrm{B} 0}-C_{\mathrm{B} \beta}}{K_{\mathrm{B} \beta} \sqrt{\pi}\left[1-\operatorname{erf}\left(K_{\mathrm{B} \beta}\right)\right]} \exp \left[-\left(K_{\mathrm{B} \beta}\right)^{2}\right] \\
& +\frac{C_{\beta \gamma}-C_{\beta \mathrm{B}}}{K_{\beta \mathrm{B}} \sqrt{\pi}\left[\operatorname{erf}\left(K_{\beta \mathrm{B}}\right)-\operatorname{erf}\left(K_{\beta \gamma}\right)\right]} \exp \left[-\left(K_{\beta \mathrm{B}}\right)^{2}\right],
\end{aligned}
$$

where $C_{\mathrm{A} 0}, C_{\mathrm{A} \gamma}, C_{\gamma \mathrm{A}}, C_{\gamma \beta}, C_{\beta \gamma}, C_{\beta \mathrm{B}}, C_{\mathrm{B} \beta}$, and $C_{\mathrm{B} 0}$ represent concentrations of the element $A$ at one side of an interface as shown in Figure 1. All the $K$ values can be calculated by these equations when the concentration profile data have been obtained.

The thickness of the two IMC phases can be simply calculated by

$$
\begin{aligned}
& l_{\gamma}=z_{b c}-z_{a b} \\
& l_{\beta}=z_{a b}-z_{b c},
\end{aligned}
$$

where $l_{\gamma}$ and $l_{\beta}$ represent the thickness of the $\gamma$-phase and the $\beta$-phase, respectively.

If the $\mathrm{Al}-\mathrm{Mg}$ binary system is taken as an example, the IMC phases to be considered are $\mathrm{Mg}_{17} \mathrm{Al}_{12}$ and $\mathrm{Al}_{3} \mathrm{Mg}_{2} \cdot{ }^{[5,9,10,12,17-19]}$ These two IMC phases have different growth kinetics during long time annealing. ${ }^{[9,10,12,13,17]}$ The $\mathrm{Mg}$ concentration at each side of every interface was obtained by thermodynamic calculations using the thermodynamic software package Pandat with the database PanAl2012. In order to calculate the values of the positions for each interface, only the $\mathrm{Mg}$ concentration profile, the interdiffusion coefficient of each phase, and the time are required as inputs. 


\section{B. Grain Boundary Diffusion}

It has been widely reported that grain boundaries can act as fast diffusion paths. ${ }^{[14,16,21]}$ According to Heitjans, ${ }^{[14]}$ the pre-exponent factor $D_{0}$ should be the same for lattice diffusion and grain boundary diffusion, but the activation energy for grain boundary diffusion is about half of that for lattice diffusion. Diffusion coefficients for lattice diffusion and grain boundary diffusion can be expressed using the classic Arrhenius relationship as shown in Eqs. [6a] and [6b], respectively $^{[14]}$ :

$$
\begin{gathered}
D_{l}=D_{0 l} \exp \left(-\frac{Q_{l}}{\mathrm{RT}}\right) \\
D_{\mathrm{gb}}=D_{0 \mathrm{gb}} \exp \left(-\frac{Q_{\mathrm{gb}}}{\mathrm{RT}}\right),
\end{gathered}
$$

where $D_{l}$ is the lattice diffusion coefficient, $D_{\mathrm{gb}}$ is the grain boundary diffusion coefficient, $D_{0 l}$ and $D_{0 \mathrm{gb}}$ are pre-exponent factors for lattice diffusion and grain boundary diffusion, $Q_{l}$ and $Q_{\mathrm{gb}}$ are the activation energies for lattice diffusion and grain boundary diffusion, respectively.

The contribution that grain boundaries can make to the overall diffusion rate also depends on the area of grain boundary per unit volume (area fraction) and grain boundary width. These factors can be combined to calculate an effective volume fraction available for grain boundary diffusion, as given by Eq. [7] $]^{[14]}$.

$$
g=\frac{q \delta}{L}
$$

where $q$ is a numerical factor depending on the grain shape, $q=1$ for columnar grains, and $q=3$ for equiaxed grains, ${ }^{[14]} \delta$ is grain boundary width, which can be approximately assumed as three times of the atomic diameter, ${ }^{[4]}$ and $L$ is grain size. Therefore, the overall effective diffusion coefficient can be calculated as weighted average of grain boundary diffusion and lattice diffusion contributions as ${ }^{[14]}$

$$
D_{\mathrm{eff}}=g D_{\mathrm{gb}}+(1-g) D_{1},
$$

where $D_{\text {eff }}$ is the overall effective diffusion coefficient.

\section{Grain Growth}

The grain size within the IMC is not usually constant but evolves due to grain growth processes as the layer thickens. This must be accounted for to accurately determine the contribution made by grain boundary diffusion. Grain growth kinetics generally follows the typical grain growth equation ${ }^{[20]}$ :

$$
L_{2}^{n}-L_{1}^{n}=k\left(t_{2}-t_{1}\right),
$$

where $L_{1}$ is the average grain size at the time $t_{1}, L_{2}$ is the average grain size at the time $t_{2}, n$ is the exponent factor, and $k$ is a constant.
Measured values of the exponent $(n)$ range from 2 to 4 for different metals. ${ }^{[20]}$ This classic grain growth model is valid for equiaxed grains. For columnar grains, which are often observed in the IMC layer formed in a diffusion couple, if only the widening of grains is considered, then Eq. [9] can also be applied, but the grain size $L$ should be the average width of the columnar grains measured from 2-D section. ${ }^{[20]}$ It is difficult to determine the appropriate values for $k$ and $n$ a priori, and so in the present work, these are derived by fitting to experimental measurements of the IMC grain size made at different times. A further complication arises because the grain size is often not uniform through the IMC layer. In this case, it is diffusion through the region of the largest grain size that will be rate limiting since there will be fewer fast diffusion pathways. Therefore, it is the grain size of the largest grain region (which usually makes up most of the layer thickness) that is used as the effective grain size in the model. This will be demonstrated for the case of the Al-Mg couple in the results section.

Once the grain size is known, the effective diffusion coefficient for the IMC phase at each temperature at each time step can be predicted using the model described in Eqs. [6] through [8]. The IMC growth kinetics can then be predicted using the multi-IMCphase diffusion model, which is expressed in Eqs. [3] through [5]. The model structure is schematically illustrated in the flow chart shown in Figure 2. If the interdiffusion coefficients of the IMC phases are unknown, the present model can also be applied to calculate the pre-exponential factor $D_{0}$ and the activation energy $Q$ of the IMC phases if the thickness of each IMC phase has been determined experimentally.

\section{RESULTS}

\section{A. Grain Growth of IMC Layers}

The $\mathrm{Mg}_{17} \mathrm{Al}_{12}$ phase and the $\mathrm{Al}_{3} \mathrm{Mg}_{2}$ phase are the two IMC phases expected to form in $\mathrm{Al}-\mathrm{Mg}$ reactive diffusion couples. In order to clearly distinguish the two IMC phases and analyze the IMC grain size, EBSD was applied to study the IMC layers. Figure 3 shows an example EBSD phase identification map after 10 minutes annealing at $673 \mathrm{~K}\left(400{ }^{\circ} \mathrm{C}\right)$. It can be seen that at short time (Figure 3(a)), the $\mathrm{Mg}_{17} \mathrm{Al}_{12}$ phase is thicker than the $\mathrm{Al}_{3} \mathrm{Mg}_{2}$ phase. After a long annealing time ( 3 hour or even 72 hour), the $\mathrm{Al}_{3} \mathrm{Mg}_{2}$ phase becomes much thicker than the $\mathrm{Mg}_{17} \mathrm{Al}_{12}$ phase [Figures 3(b) and (c)]. Further details are given elsewhere. ${ }^{[5]} \mathrm{Mg}_{17} \mathrm{Al}_{12}$ phase is the first formed IMC phase, but the $\mathrm{Al}_{3} \mathrm{Mg}_{2}$ phase has a faster growth rate. Therefore, as the annealing time is increased, the $\mathrm{Al}_{3} \mathrm{Mg}_{2}$ phase eventually becomes thicker than the $\mathrm{Mg}_{17} \mathrm{Al}_{12}$ phase. In each sample, the grain size of the $\mathrm{Mg}_{17} \mathrm{Al}_{12}$ phase is quite uniform, and thus applying the average grain size for the modeling calculation is acceptable. However, the grain size for $\mathrm{Al}_{3} \mathrm{Mg}_{2}$ phase varies with the distance to the $\mathrm{Al}$ substrate. New small $\mathrm{Al}_{3} \mathrm{Mg}_{2}$ grains always nucleate at 


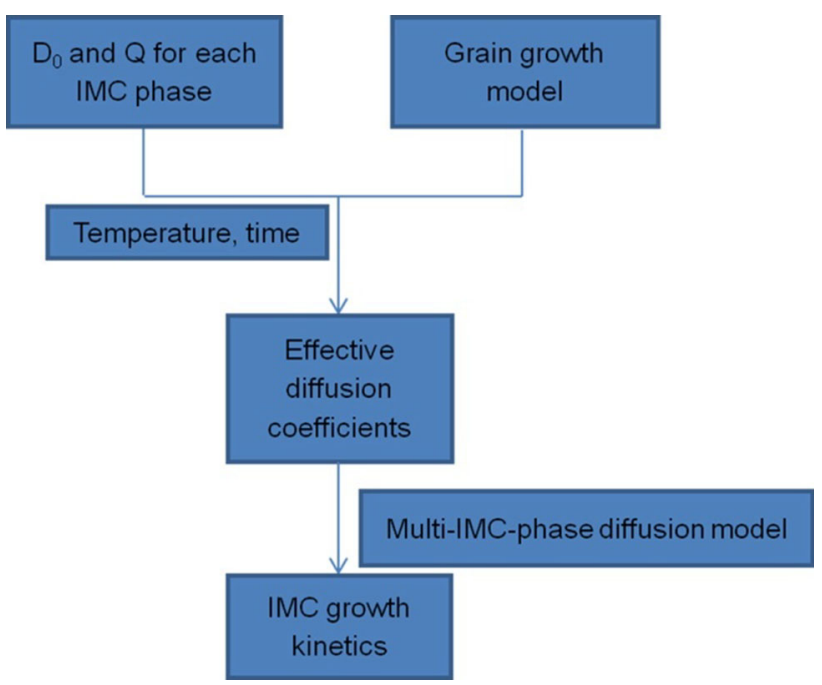

Fig. 2-Schematic illustration of applying the model to predict IMC growth kinetics.

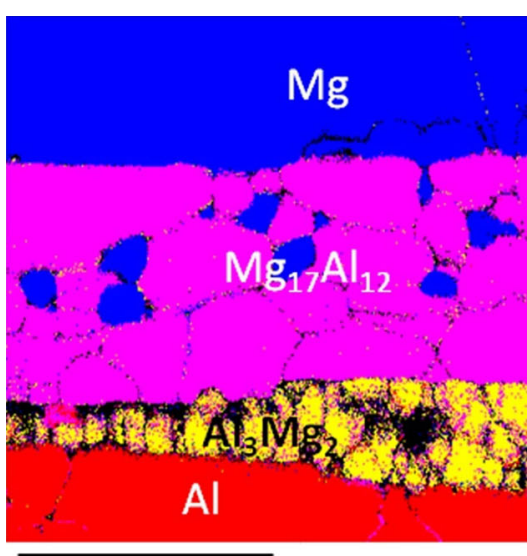

(a)

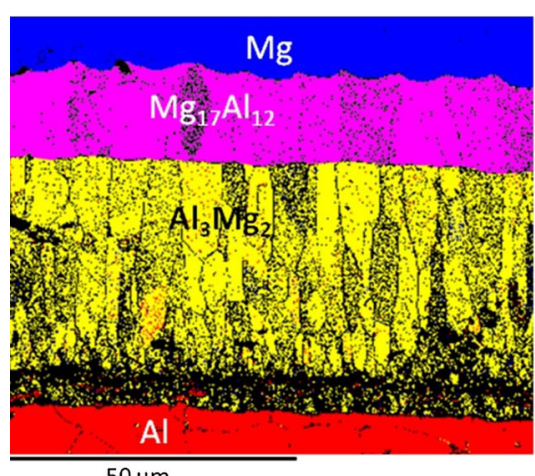

(b)
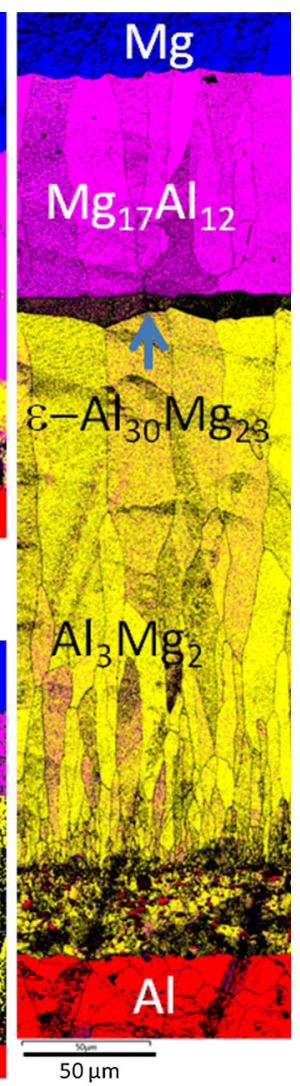

(c)
Fig. 3-EBSD images of the reactive diffusion interface between $\mathrm{Al}$ alloy and $\mathrm{Mg}$ alloy after long time isothermal heat treatment $(a)$ $10 \mathrm{~min},(b) 3 \mathrm{~h}$, and (c) 72 hour, at $673 \mathrm{~K}\left(400{ }^{\circ} \mathrm{C}\right)$.

the interface between $\mathrm{Al}_{3} \mathrm{Mg}_{2} / \mathrm{Al}$ with the thickening of the $\mathrm{Al}_{3} \mathrm{Mg}_{2}$ phase, and they increase in size toward the interface between $\mathrm{Al}_{3} \mathrm{Mg}_{2} / \mathrm{Mg}_{17} \mathrm{Al}_{12}$. Near the interface to the $\mathrm{Mg}_{17} \mathrm{Al}_{12}$ phase, the $\mathrm{Al}_{3} \mathrm{Mg}_{2}$ grains can be as large as the $\mathrm{Mg}_{17} \mathrm{Al}_{12}$ grains. This change in grain size can clearly be seen in Figure 3. As discussed previously, the rate-limiting step will be the diffusion through material with the largest grain size. Therefore, in the model, the grain size at the largest grain region is applied in Eq. [8] to calculate the effective diffusion coefficient $D_{\text {eff }}$ of the IMC layer.

From Figure 3(c), a tertiary IMC phase is present at the interface between the $\mathrm{Mg}_{17} \mathrm{Al}_{12}$ phase and the $\mathrm{Al}_{3} \mathrm{Mg}_{2}$ phase after a long time heat treatment at $673 \mathrm{~K}\left(400{ }^{\circ} \mathrm{C}\right)$. There are a number of candidate tertiary IMC phases that can form after long time annealing of Al-Mg couples. ${ }^{[22-24]}$ Possible phases include $\varepsilon$-phase, $R$-phase, $\lambda$-phase, or $\zeta$-phase. EDX analysis of the phase composition shows it contains $\sim 56$ at. pct $\mathrm{Al}$, which best matches the expected chemistry for $\varepsilon$-phase. This phase only formed after very extended (e.g., $72 \mathrm{~h})$ isothermal heat treatment, and does not normally arise in the timescale used for industrial dissimilar metal joining processes. Therefore, it is not considered in the present modeling calculation.

The thickness data and the grain size data obtained from the present experimental results are shown in Figure 4 at different temperatures and times. The grain size data are measured from 2-D section to get the true grain size. The growth behaviors of each IMC layer at various temperatures are plotted in Figures 4(a) and (b). The growth kinetics of the $\mathrm{Al}_{3} \mathrm{Mg}_{2}$ phase is always faster than the $\mathrm{Mg}_{17} \mathrm{Al}_{12}$ phase at the temperature range, and the kinetics curves of both the IMC phases generally follow the parabolic relationship with time. Figure 4(c) shows the average grain width measured from a 2-D section of $\mathrm{Mg}_{17} \mathrm{Al}_{12}$, and Figure 4(d) shows the average grain width measured from a 2-D section of $\mathrm{Al}_{3} \mathrm{Mg}_{2}$ in the region close to the interface where the grain size is largest. From the grain size data in Figures 4(c) and (d), the grain growth behavior at these temperatures generally follows the parabolic relationship in Eq. [9] with the exponent factor $n=2$. In Figures 4(a) and (b), the error bars are standard deviations of IMC thickness measured at five different positions. In Figures 4(c) and (d), the error bars are standard deviations of the width of all measured grains in a sample.

\section{B. IMC Thickness Prediction}

The model to predict the IMC thickness evolution for both $\mathrm{Mg}_{17} \mathrm{Al}_{12}$ and $\mathrm{Al}_{3} \mathrm{Mg}_{2}$ phases was implemented in MATLAB based on the theory already presented. Equilibrium compositions of the phases at the interfaces were calculated as a function of temperature using Pandat as already described.

To predict the IMC growth kinetics, the model requires diffusion data for both grain boundary and lattice diffusion. The diffusion data available in the literature extracted from measuring IMC thickening rates provides only an effective value for activation energy that combines both grain boundary and lattice diffusion. ${ }^{[12,13]}$ If these values are used as inputs to the model (assuming they apply to lattice diffusion only), then as shown in Figure 5 the thickening rates are 
always overestimated by the model. This is because the contribution from grain boundary and lattice diffusion is not properly considered separately as required by the model. These calculations demonstrate that values of $D_{0}$ and $Q$ from the literature cannot be directly applied in the present model, but the new accurate values of

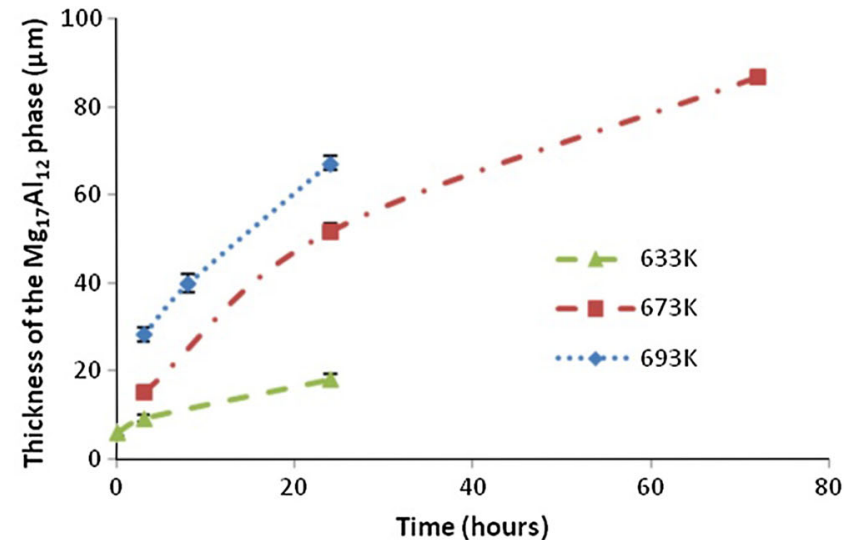

(a)

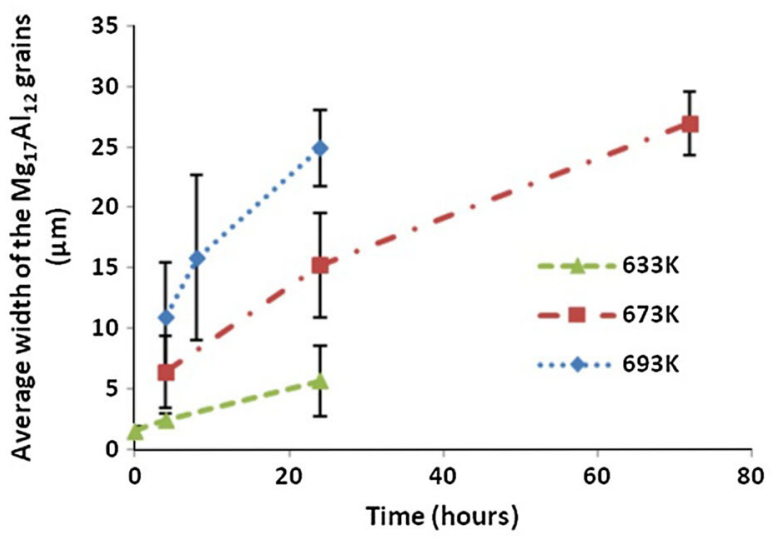

(c)

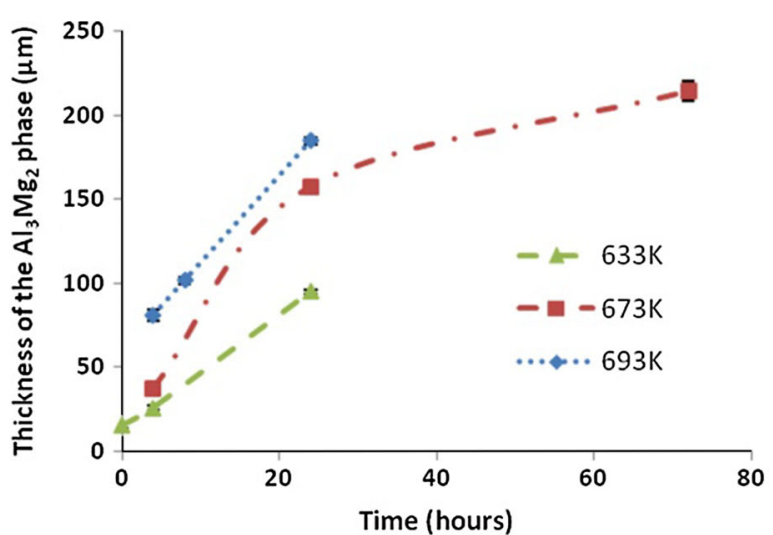

(b)

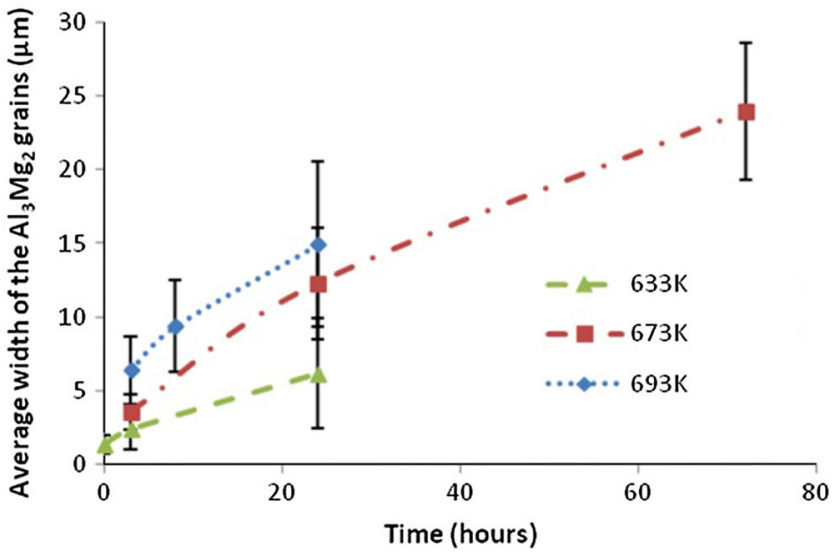

(d)

Fig. 4-Experimental measurement of (a) IMC thickness of the $\mathrm{Mg}_{17} \mathrm{Al}_{12}$ phase, $(b)$ IMC thickness of the $\mathrm{Al}_{3} \mathrm{Mg}_{2}$ phase, $(c)$ average width measured from 2-D section of the uniform $\mathrm{Mg}_{17} \mathrm{Al}_{12}$ grains, and $(d)$ average width measured from 2-D section of the $\mathrm{Al}_{3} \mathrm{Mg}_{2}$ grains close to the interface between the two intermetallic phases, after heat treatment at various temperatures for various times.

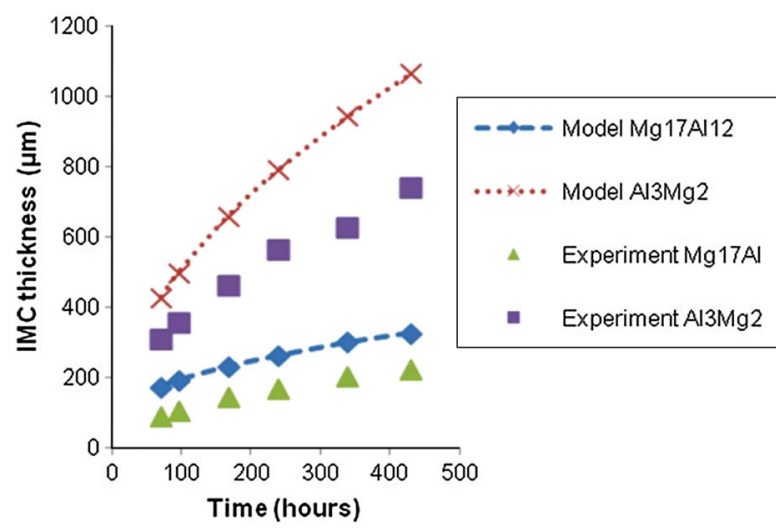

(a)

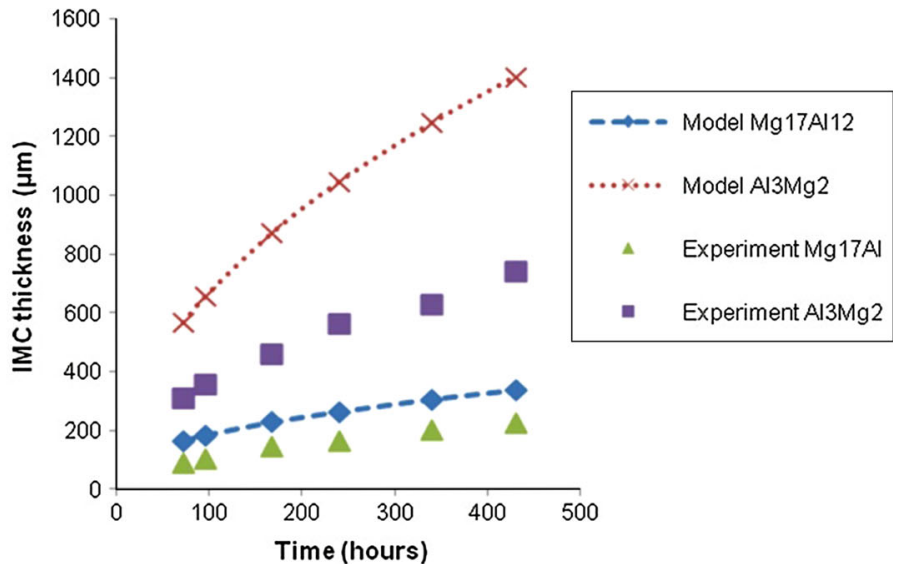

(b)

Fig. 5-Incorporating diffusion coefficient data from the literature into the model and comparing with experimental measured IMC thickness after isothermal heat treatment at $673 \mathrm{~K}\left(400{ }^{\circ} \mathrm{C}\right):(a)$ diffusion coefficient data from Brennan ${ }^{[6]}$ and $(b)$ diffusion coefficient data from Das. ${ }^{[7]}$ 
diffusion coefficient parameters including $D_{0 l}, D_{0 \mathrm{gb}}, Q_{l}$, and $Q_{\mathrm{gb}}$ are necessary.

\section{Interdiffusion Coefficients Calculation}

The present model can also be utilized to calculate the interdiffusion coefficients of IMC phases. In order to calculate the interdiffusion coefficients of the two IMC phases, the grain growth kinetics of each IMC phase and the thickness of each IMC layer after a heat treatment are required. The self-diffusion coefficient of $\mathrm{Mg}$ and $\mathrm{Al}$ are obtained from Brennan. ${ }^{[6]}$ The effective interdiffusion coefficients of the $\mathrm{Mg}_{17} \mathrm{Al}_{12}$ phase and the $\mathrm{Al}_{3} \mathrm{Mg}_{2}$ phase can be calculated by Eqs. [3] through [5]. The individual contributions from lattice and grain boundary diffusion can then be calculated using the measured grain size data at each isothermal holding time as shown in Figure 4(b). The calculated $D_{0}$ and $Q$ values for both mechanisms are as shown in Table I.

With the diffusion coefficient data from Table I, the present model was also utilized to predict the thickness of IMC layers at different temperatures. Modeling predictions are compared with experimental measured IMC growth for Al-Mg couples with different initial conditions taken from the literature ${ }^{[10,25]}$ as shown in Figure 6. The experimental data in Figure 6(a) are from Panteli. ${ }^{[25]}$ In that study, couples between $\mathrm{Al}$ alloy (AA6111) and Mg alloy (AZ31) were lightly welded before the heat treatment, and thus the sample conditions should be quite similar to those in the present work. The experimental data in Figure 6(b) were from a different technique, that of diffusion bonding of pure $\mathrm{Al}-\mathrm{Mg}$ couples with no pre-welding, only contact under pressure. ${ }^{[10]}$ The IMC grain size data were not measured in these studies. ${ }^{[10,25]}$ Therefore, it was assumed that the initial grain size in the IMC layer was the same as that measured in the present work, but subsequent grain growth was allowed to vary as a function of temperature according to the grain growth model already outlined. The good agreement between predictions and experiments suggests that an accurate a priori knowledge of the initial grain size in the IMC is not needed for the present model to be used successfully, because the grain size during most of the IMC thickening time is determined more strongly by the temperature at which grain growth occurs.

\section{DISCUSSION}

Thickening of the intermetallic compound layers during reactive interdiffusion involves both lattice and grain boundary diffusion through the layer. The competition between these two diffusion mechanisms can be analyzed using the present model. From Eq. [8], the dominant diffusion pathway is largely dependent on the grain size. If the temperature is fixed at $673 \mathrm{~K}\left(400{ }^{\circ} \mathrm{C}\right)$ which is a typical temperature used to produce $\mathrm{Al}-\mathrm{Mg}$ diffusion couples, the effect of grain size on the contributions of grain boundary diffusion and lattice diffusion to the overall effective diffusion coefficient is as shown in Figures 7(a) and (b). In Figure 7(a), it can be seen that grain boundary diffusion dominates lattice diffusion for the $\mathrm{Mg}_{17} \mathrm{Al}_{12}$ phase at $673 \mathrm{~K}\left(400{ }^{\circ} \mathrm{C}\right)$ across the whole range of grain sizes observed experimentally (up to $25 \mu \mathrm{m}$ ) and thus the effective diffusion coefficient is primarily controlled by grain boundary diffusion. However, Figure 7(b) shows that grain boundary diffusion only has a dominant effect on the effective diffusion coefficient for the $\mathrm{Al}_{3} \mathrm{Mg}_{2}$ phase at $673 \mathrm{~K}\left(400{ }^{\circ} \mathrm{C}\right)$ when the grain size is very small $(<2 \mu \mathrm{m})$, otherwise lattice diffusion becomes more important.

Table I. Diffusion Coefficient Parameters for the Two IMC Phases Considering the Effect of Grain Boundary Diffusion

\begin{tabular}{lcccc}
\hline Phase & $D_{01}\left(\mathrm{~m}^{2} / \mathrm{s}\right)$ & $D_{0 \mathrm{gb}}\left(\mathrm{m}^{2} / \mathrm{s}\right)$ & $Q_{1}(\mathrm{~kJ} / \mathrm{mol})$ & $Q_{\mathrm{gb}}(\mathrm{kJ} / \mathrm{mol})$ \\
\hline $\mathrm{Mg}_{17} \mathrm{Al}_{12}$ & $4.0 \mathrm{e}-3$ & $4.0 \mathrm{e}-3$ & 155 & 78 \\
$\mathrm{Al}_{3} \mathrm{Mg}_{2}$ & $8.5 \mathrm{e}-6$ & $8.5 \mathrm{e}-6$ & 90 & 45 \\
\hline
\end{tabular}

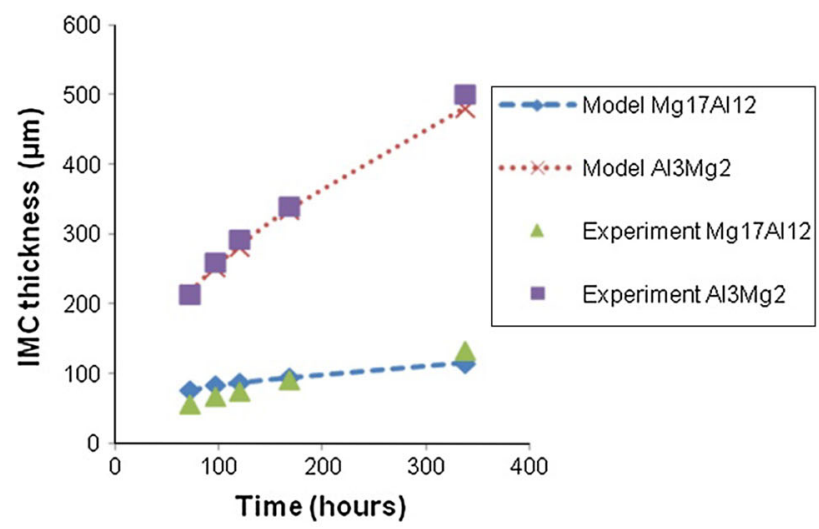

(a)

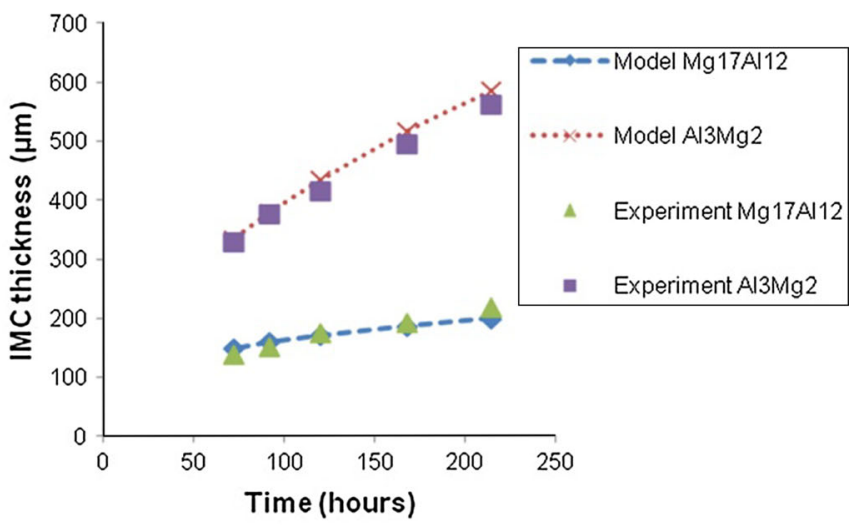

(b)

Fig. 6 - Comparisons between the modeling predictions and the experimental results ${ }^{[10,25]}$ during long time static heat treatment between $\mathrm{Al}$ and $\mathrm{Mg}$ at $(a) 653 \mathrm{~K}\left(380^{\circ} \mathrm{C}\right)$ and $(b) 697 \mathrm{~K}\left(424^{\circ} \mathrm{C}\right)$. 


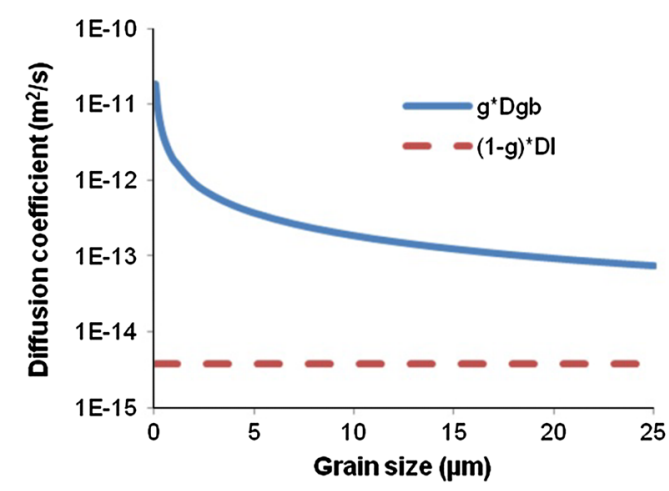

(a)

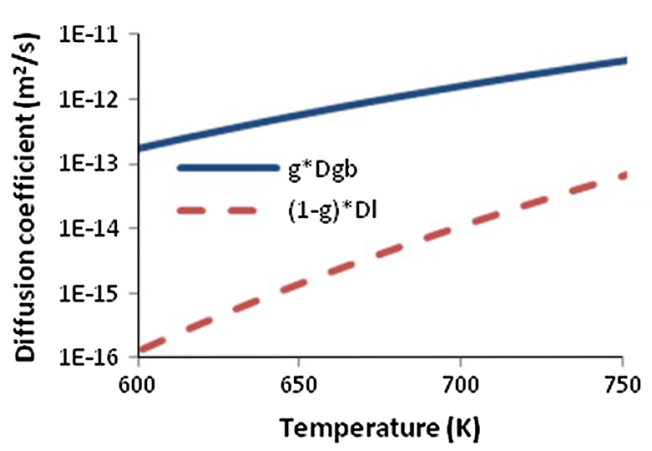

(c)

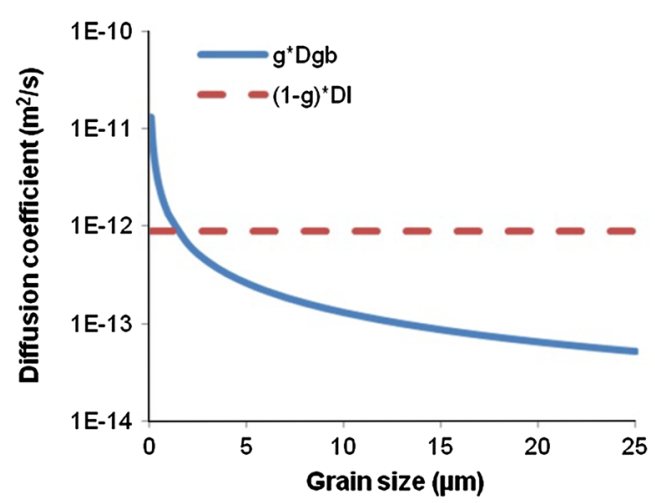

(b)

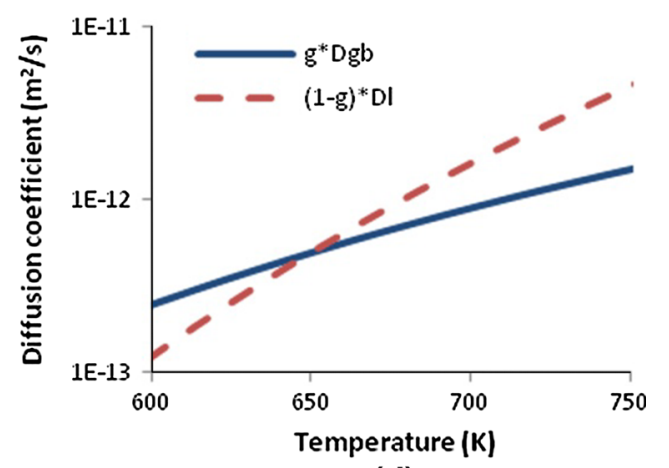

(d)

Fig. 7-(a) Effects of width of grains on diffusion coefficient of $\gamma-\mathrm{Mg}_{17} \mathrm{Al}_{12}$ at $673 \mathrm{~K}\left(400{ }^{\circ} \mathrm{C}\right)$; $(b)$ Effects of width of grains on diffusion coefficient of $\beta-\mathrm{Al}_{3} \mathrm{Mg}_{2}$ at $673 \mathrm{~K}\left(400{ }^{\circ} \mathrm{C}\right)$; (c) Effects of temperature on grain boundary diffusion for $\gamma-\mathrm{Mg}_{17} \mathrm{Al}_{12}$ if the grain width is fixed at $2 \mu \mathrm{m}$; (d) Effects of temperature on grain boundary diffusion for $\beta-\mathrm{Al}_{3} \mathrm{Mg}_{2}$ if the grain width is fixed at $2 \mu \mathrm{m}$.

The transition from grain boundary to lattice-dominated diffusion is temperature dependent and this can be seen by comparing the contributions assuming a fixed grain size of $2 \mu \mathrm{m}$. This small grain size is typical of that observed during the early stages of IMC growth. Diffusion coefficients for the $\mathrm{Mg}_{17} \mathrm{Al}_{12}$ phase and the $\mathrm{Al}_{3} \mathrm{Mg}_{2}$ phase for this grain size are plotted as a function of temperature in Figures 7(c) and (d), respectively. In the temperature range $600 \mathrm{~K}$ to $750 \mathrm{~K}\left(327^{\circ} \mathrm{C}\right.$ to $477^{\circ} \mathrm{C}$ ), which is the typical temperature range during solid-state welding between $\mathrm{Al}$ and $\mathrm{Mg}$, grain boundary diffusion is predicted to dominate for the $\mathrm{Mg}_{17} \mathrm{Al}_{12}$ phase, but the effective diffusion coefficient for the $\mathrm{Al}_{3} \mathrm{Mg}_{2}$ phase transitions from grain boundary to lattice dominated at about $650 \mathrm{~K}\left(377^{\circ} \mathrm{C}\right)$.

The reason for the different controlling mechanisms for the two IMC phases in the $\mathrm{Al}-\mathrm{Mg}$ couple is the difference in activation energy of diffusion in each phase. According to the present results, and consistent with data from the literature, ${ }^{[10,12,13]}$ the $\mathrm{Mg}_{17} \mathrm{Al}_{12}$ phase has much higher activation energy for lattice diffusion than the $\mathrm{Al}_{3} \mathrm{Mg}_{2}$ phase. The higher activation energy for diffusion in the $\mathrm{Mg}_{17} \mathrm{Al}_{12}$ phase makes lattice diffusion more difficult, and therefore, the reduction in activation energy associated with grain boundaries has a stronger effect on $D$. This effect can be seen by considering the influence of changing activation energy for a fixed temperature and grain size.

The effect of activation energy on the coefficients for grain boundary and lattice diffusion at $673 \mathrm{~K}\left(400{ }^{\circ} \mathrm{C}\right)$

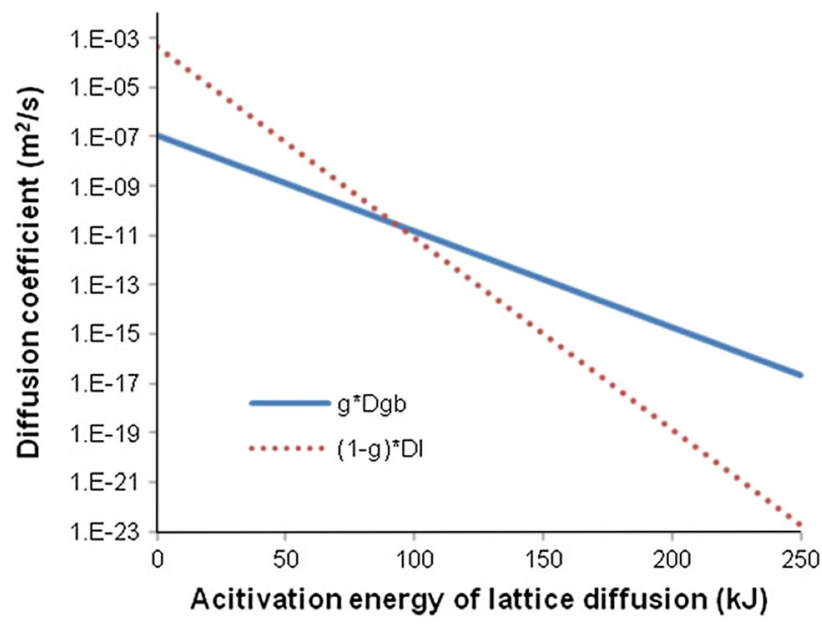

Fig. 8-Effects of activation energy of lattice diffusion on the competition between grain boundary diffusion and lattice diffusion for a phase with $2-\mu \mathrm{m}$ grain width at $673 \mathrm{~K}\left(400^{\circ} \mathrm{C}\right)$.

with a fixed grain width of $2 \mu \mathrm{m}$ is plotted in Figure 8 . This shows the expected activation energy for lattice diffusion at which a transition from lattice to grain boundary diffusion will dominate.

In this paper, the model is applied for the $\mathrm{Al}-\mathrm{Mg}$ couple where two typical IMC phases could be formed. However, the model can also be utilized to predict IMC 
growth behavior or calculate diffusion coefficients for other couples of dissimilar metals where one or more IMC phases could be formed.

\section{CONCLUSIONS}

A new model has been developed to predict growth kinetics of IMC layers. The model solves the growth kinetics by explicitly accounting for both grain size effects and multiple IMC layers forming together. The model is applied to the case of $\mathrm{Al}-\mathrm{Mg}$ bonding in which two main IMC phases form $\left(\mathrm{Mg}_{17} \mathrm{Al}_{12}\right.$ and $\left.\mathrm{Al}_{3} \mathrm{Mg}_{2}\right)$ both of which have a different grain structure that evolves during heat treatment. The model has been successfully used to predict the growth kinetics of the IMC layers in Al-Mg couples with different initial processing conditions heat treated at different temperatures. The model enables the effect of grain size on IMC thickening rates to be explored and demonstrates that for some IMC phases (i.e., $\mathrm{Mg}_{17} \mathrm{Al}_{12}$ in this case) grain boundary diffusion will be dominant under typical industrial conditions, whereas for others (i.e., $\mathrm{Al}_{3} \mathrm{Mg}_{2}$ ) lattice diffusion will dominate. These results are useful in developing methods to slow down IMC thickening rates to improve the performance of dissimilar metal Al-Mg joints. For example, for phases where grain boundary diffusion dominates, alloying with dopants that segregate to the grain boundary may be effective in blocking diffusion pathways and slowing thickening kinetics.

\section{ACKNOWLEDGMENTS}

The authors gratefully thank to EPSRC for funding this work through program Grant EP/H020047/1, Light Alloys for Sustainable Transport (LATEST2).

\section{OPEN ACCESS}

This article is distributed under the terms of the Creative Commons Attribution 4.0 International License (http://creativecommons.org/licenses/by/4.0/), which permits unrestricted use, distribution, and reproduction in any medium, provided you give appropriate credit to the original author(s) and the source, provide a link to the Creative Commons license, and indicate if changes were made.

\section{REFERENCES}

1. M. Kajihara: Acta Mater., 2004, vol. 52, pp. 1193-1200.

2. M. Kajihara: Mater. Sci. Eng. A, 2005, vol. 403, pp. 234-40.

3. H. Springer, A. Kostka, E.J. Payton, D Raabe, A. Kaysser-Pyzalla, and G. Eggeler: Acta Mater., 2011, vol. 59, pp. 1586-1600.

4. J.D. Robson: Acta Mater., 2013, vol. 61, pp. 7781-90.

5. A. Panteli, J.D. Robson, I. Brough, and P.B. Prangnell: Mater. Sci. Eng. A, 2012, vol. 556, pp. 31-42.

6. D.H. Choi, B.W. Ahn, C.Y. Lee, Y.M. Yeon, K. Song, and S.B. Jung: Intermetallics, 2011, vol. 19, pp. 125-30

7. L. Liu, H. Wang, G. Song, and J. Ye: J. Mater. Sci., 2007, vol. 42, pp. $565-72$.

8. A. Panteli, J.D. Robson, Y.C. Chen, and P.B. Prangnell: Metall. Mater. Trans. A, 2013, vol. 44A, pp. 5773-81.

9. J. Robson, A. Panteli, and P.B. Prangnell: Sci. Technol. Weld. Join., 2012, vol. 17, pp. 447-53.

10. E.M. Tanguep Njiokep, M. Salamon, and H. Mehrer: Defect Diffus. Forum, 2001, vols. 194-199, pp. 1581-86.

11. C.V. Kidson: J. Nucl. Mater., 1961, vol. 3, pp. 21-29.

12. P. Heitjans and J. Kärger: Diffusion in Condensed Matter: Methods, Materials, Models, Springer, Heidelberg, 2005, pp. 337-66.

13. C. Matano: Jpn. J. Phys., 1933, vol. 8, pp. 109-13.

14. S. Brennan, K. Bermudez, N.S. Kulkarni, and Y. Shon: Metall. Mater. Trans. A, 2012, vol. 43A, pp. 4043-52.

15. S.K. Das, Y.M. Kim, T.K. Ha, R. Gauvin, and I.H. Jung: Metall. Mater. Trans. A, 2013, vol. 44A, pp. 2539-47.

16. R.S. Barnes: Nature, 1950, vol. 166, pp. 1032-33.

17. L.G. Harrison: Trans. Faraday Soc., 1961, vol. 57, pp. 1191-99.

18. D. Dietrich, D. Nickel, M. Krause, T. Lampke, M.P. Coleman, and V. Randle: J. Mater. Sci., 2011, vol. 46, pp. 357-64.

19. J. Yan, Z. Xu, Z. Li, L. Li, and S. Yang: Scripta Mater., 2005, vol. 53, pp. 585-89.

20. Z.F. Li, J. Dong, XQ Zeng, C. Lu, W.J. Ding, and Z.M. Ren: J. Alloys Compd., 2007, vol. 440, pp. 132-36.

21. F.J. Humphreys and M. Hatherly: Recrystallization and related annealing phenomena, Elsevier, Oxford, 1996, pp. 333-78.

22. H.L. Su, M. Harmelin, P. Donnadieu, C. Baetzner, H.J. Seifert, H.L. Lukas, G. Effenberg, and F. Aldinger: J. Alloys Compd., 1997, vol. 247, pp. 57-65.

23. T. Czeppe, W. Zakulski, and E. Bielanska: J. Phase Equilib., 2003, vol. 24 , pp. 249-54.

24. N.C. Goel, J.R. Cahoon, and B. Mikkelsen: Metall. Trans. A, 1989, vol. 20A, pp. 197-203.

25. Panteli A.: Friction Joining of Aluminium-to-Magnesium for Lightweight Automotive Applications: $\mathrm{PhD}$ thesis, The University of Manchester, Manchester, UK, 2012, pp. 216-239. 